\title{
INJURIES IN HIGH SCHOOL LEVEL RUGBY UNION: HOW DO COACHES MANAGE INJURIES?
}

original paper

( ) University School of Physical Education in Wroclaw

DOI: https://doi.org/10.5114/hm.2021.98464

\section{LEE POTE, BRADLEY ROBINSON, CANDICE CHRISTIE}

Rhodes University, Makhanda, South Africa

\begin{abstract}
Purpose. The purpose of the investigation was to determine the injuries and injury prevention strategies in high school rugby union players, as reported by the coaches.

Methods. A cross-sectional, descriptive study was conducted where participants (from fee-paying and no-fee-paying schools) were required to complete an electronically based questionnaire focusing specifically on injuries and injury prevention strategies in male high school level rugby players.

Results. The results indicated that the most common injured position was the back row, while $60 \%$ of all injuries were to the shoulder region. Furthermore, while the majority $(75 \%)$ of coaches did record injury statistics, only a limited number implemented injury prevention strategies (mainly from fee-paying schools). The most common injury prevention tool reported was 'strengthening target areas'.

Conclusions. It was concluded that all schools should monitor injuries and implement some form of strength and conditioning program to reduce the risk of player injury. Furthermore, it was noted that for this to occur, the education of the coach as well as the player was highly important.
\end{abstract}

Key words: prevention, training, coaching

\section{Introduction}

Rugby has a higher risk of injury than many other team sports, which is commonly attributed to the contact nature of the game [1-3]. More injuries occur during match play (approximately 80-90\% of all injuries) compared with practice, with the highest incidence in elite players [3, 4]. Additionally, there is an increased injury incidence in the second half of a rugby match owing to player fatigue and higher match intensity $[4,5]$. During matches, head/face $(22.0 \%)$, knee $(16.2 \%)$, muscle-strain (23.1\%), and ligament-sprain (23.1\%) are the most common locations and types of injuries [6]. In elite level rugby, the most common mechanism for injury in backline players is the tackle (24.7\%), while the ruck or maul is most dangerous for forwards [3, 4]. The tackle event has a high injury rate for both players involved and results in 5 times more injuries than any other contact scenario in rugby union [7, 8]. However, the act of tackling accounts for fewer injuries (18.5-
$40.0 \%)$ than being the recipient of a tackle (16.5-65.0\%) $[6,7]$. It is also the most likely cause of injury in high school rugby, with an incidence of $62.1 \%$ [9]. Other comparable events contributing to injuries include the ruck, causing $24.3 \%$, and scrums, causing $5.4 \%$ [9].

Furthermore, the tackle is also responsible for a high proportion of upper body injuries such as head/ neck injuries and concussions while the player being tackled is more susceptible to lower body injuries such as knee and thigh injuries [7, 10,11].

Among adolescents, soft tissue damage, including sprains and ligament injuries, is the most common type of injury (Table 1) [9, 12]. The least common types are dislocations and subluxations (0.5-10.8\%). Concussions and head injuries, while relatively rare compared with other injuries, constitute a critical area of research owing to their severity [9, 12]. Again, the tackle event is most commonly responsible for concussion injuries, often caused by improper tackle technique [7]. A general lack of skill from the tackler has been highlighted as

Correspondence address: Lee Pote, Rhodes University, Department of Human Kinetics and Ergonomics, Upper African Street, Makhanda, 6139, South Africa, e-mail: l.pote86@gmail.com

Received: September 4, 2019

Accepted for publication: February 22, 2020

Citation: Pote L, Robinson B, Christie C. Injuries in high school level rugby union: how do coaches manage injuries? Hum Mov. 2021;22(1):50-56; doi: https://doi.org/10.5114/hm.2021.98464. 
Table 1. Percentage of all injuries by nature of injury according to 19 studies of children and adolescent rugby players

\begin{tabular}{lc}
\hline Injury & $\begin{array}{c}\text { Percentage of } \\
\text { all injuries }\end{array}$ \\
\hline Ligament injuries, sprains, and strains & $15.7-47.2 \%$ \\
Laceration, contusion, and haematoma & $2.7-46.0 \%$ \\
Fracture & $3.0-27.0 \%$ \\
Concussion & $2.2-24.6 \%$ \\
Dislocation and subluxation & $0.5-10.8 \%$ \\
\hline
\end{tabular}

a risk factor to concussions and a main cause of these injuries in high school rugby in South Africa [13]. A study which looked at a South African high school first rugby team also emphasized an increase in injury incidence when players were exposed to both provincial and school level rugby concurrently, suggesting that this may be a workload issue [14]. Furthermore, injury incidence rose with age and competition level and so the level of play is important to consider [15].

Another important factor to take into account when looking at injuries at the schoolboy level is the schooling system that the players are exposed to. The South African high school education system distinguishes two broad types of schools, namely private independent schools and public schools. Private independent schools serve the upper class population of South Africa, but only involved $4.1 \%$ of the enrolled student population in 2014 [16]. These schools have the autonomy to choose the best education system and appropriate allocation of resources at their disposal. Public schools in South Africa are characterized by deep inequalities that reveal a reality whereby two systems exist: one for the middle class population (the population falling between the working and upper classes) and one for the majority (mostly black) population [17]. Furthermore, public schools can be divided into no-fee-paying and fee-paying ones. The gap between the two can be large, with the dysfunctional no-fee-paying schools catering for the economically disadvantaged students [17].

At the international level, rugby has the highest incidence of injury and importance is placed on them [10]. In contrast, injuries at a junior level are often dismissed as 'part of the game,' which could lead to a much higher risk [9]. This is highlighted by the fact that most studies have focused on reducing the risk of injury at the senior level. Very few studies have looked at injury incidence and risk in adolescent players, particularly within the South African context. This may be because of a lack of medical assistance for school teams where coaches or strength and conditioning specialists are often the individuals responsible for keeping a record of injuries and ensuring players are prepared or being treated when needed. The extent to which this is done is not really known. Thus, the purpose of this investigation was to determine the injuries and injury prevention strategies as reported by the coaches, strength and conditioning specialists, or medical staff of first rugby teams.

\section{Material and methods}

\section{Experimental approach to the problem}

The investigation was a cross-sectional descriptive study that requested participation in an electronically based survey questionnaire (www.kwiksurvey.com). The questionnaire design followed a literature review of previous surveys and questionnaires examining similar issues, particularly those regarding rugby and injury-related research [18-20]. However, owing to the limited literature available, particularly with regard to rugby-specific questions, newly constructed questions were verified for construct validity through pilot testing with local strength and conditioning specialists, sports scientists, and coaches.

The survey consisted of two sections:

1. Injuries and injury prevention section: This included questions regarding the current injury status of players as well as methods implemented for injury prevention. For the purpose of this study, injuries were defined as either a medical attention (an injury requiring medical attention) or a time loss injury (more than one day off from training or matches).

2. General comments: This section was included to allow coaches an opportunity to include any information they might deem useful to the study.

Lastly, the survey consisted of both quantitative and qualitative questions. Quantitative questions provided specific data that were transformed into useable statistics. These questions included a combination of nominal and interval levels of measurement that reflected the response frequencies. The qualitative questions revealed specific trends or opinions and ensured the participants were not limited in their answers.

\section{Participants}

The participants recruited were the head strength and conditioning specialists, coaches, or medical professionals at the top 100 (U-19 level) rugby schools in South Africa. The final sample comprised individuals from 12 private schools, 16 public schools, and 15 
no-fee-paying schools. All subjects were informed of the study benefits and risks before providing their consent to participate.

\section{Procedures}

The survey was e-mailed to the participants at each school. E-mail addresses were attained via the school's website. The e-mail contained the information to the participant and a link to the online website. It also explained that the subjects were under no obligation to complete the questionnaire and could decline participation at any point. If an individual was unavailable via e-mail, a face-to-face interview was arranged where possible. Because of the multi-lingual nature of the South African education system, it was expected that there would be some language barriers. Thus, faceto-face interviews were also deemed necessary in assisting with the understanding of certain concepts and questions. During these interviews, the respondents were not influenced in any way but explanations were provided for some terms where needed.

\section{Statistical analyses}

Quantitative data were analysed with a data analysis tool used by the KwikSurvey website. These responses were then exported by the survey host (KwikSurvey) to a Microsoft Excel spreadsheet. Thematic analysis was applied for qualitative data to identify patterns of meaning across the datasets that provided insight into the relevant question being addressed. This employed the process of data familiarization, data coding, theme development, and revision. Patterns or themes were identified in accordance with the methods used in previous publications. Braun and Clarke [21] recognized a 6-phase process of thematic analysis that was closely followed in the current study. The qualitative questions were collated and content was analysed for specific major and minor themes. Categorical and ordinal data were reported as percentages of total responses. Univariate analysis was used to describe the basic features of the data and was stratified by the types of schools involved in the study.

\section{Ethical approval}

The research related to human use has complied with all the relevant national regulations and institutional policies, has followed the tenets of the Declaration of Helsinki, and has been approved by the Department of Human Kinetics and Ergonomics Ethical Standards Committee for research involving human participants (Rhodes University, Makhanda, South Africa; approval number: HKE-2017-02).

\section{Informed consent}

Informed consent has been obtained from all individuals included in this study.

\section{Results}

Overall, 25 participants (private: $67 \%$, public: $81 \%$, no-fee-paying: $20 \%$ ) reported recording injury incidence amongst their players (only $25 \%$ of the top 100 schools responded, which may be seen as a limitation). The most commonly injured position was reported to be the back row, with 8 responses (private: $22 \%$, public: 50\%, no-fee-paying: 0\%) (Table 2).

The most common sites of injury were shoulders, with 52 recordings of shoulder injuries $(60 \%$ of total injuries) (Table 3). Ankle injuries were common $(n=40)$ and similar in the back row, half backs, and outside backs (32\%). Hamstring (52\%) and calf muscle (32\%) injuries were most common in outside backs (52\%). Groin injuries were most prevalent in half backs (32\%). Head injuries occurred most often among front row and back row players, with a prevalence of $24 \%$ each. The front row suffered the greatest number of lower back injuries (28\%). Overall, the back row had the highest number of reported injuries $(n=45)$.

A total of 25 coaches reported employing injury prevention exercises (Table 4). The majority of private (83\%) and public school (94\%) coaches stated that they utilized injury prevention exercises while only 1 non-fee-paying school coach maintained that they did. The most popular injury prevention exercises were strengthening target areas $(n=13$, private: $60 \%$, public: $43 \%$, no-fee-paying: $100 \%$ ); however, it should be noted that only 1 no-fee-paying school implemented these types of exercises. Eccentric work (private: $40 \%$, public: $14 \%$, no-fee-paying: $100 \%$ ) as well as balance, stability, and movement exercises (private: $30 \%$, public: 29\%, no-fee-paying: $0 \%$ ) each received 7 responses. Core exercises, flexibility, recovery techniques, and high-speed exertions were also included as forms of injury prevention. Furthermore, injury prevention strategies were mostly implemented in the pre-season, followed by the in-season and then by the off-season.

\section{Discussion}

The majority (75\%) of the respondents did record injuries of their players. However, the fact that $25 \%$ did not record any injury statistics is an area of concern. 
Table 2. Most commonly reported injured positions

\begin{tabular}{lcccccc}
\hline School type & Front row (\%) & Second row (\%) & Back row (\%) & Half backs (\%) & Centres (\%) & Outside backs (\%) \\
\hline Private $(n=9)$ & $3(33)$ & $1(11)$ & $2(22)$ & $0(0)$ & $1(11)$ & $2(22)$ \\
Public $(n=12)$ & $0(0)$ & $2(17)$ & $6(50)$ & $0(0)$ & $3(25)$ & $1(8)$ \\
No-fee-paying $(n=4)$ & $2(50)$ & $0(0)$ & $0(0)$ & $0(0)$ & $1(25)$ & $1(25)$ \\
Total $(n=25)$ & $5(20)$ & $3(12)$ & $8(32)$ & $0(0)$ & $5(20)$ & $4(16)$ \\
\hline
\end{tabular}

Table 3. Most common injury sites for specific positions (excluding no-fee-paying schools and those who did not record injuries)

\begin{tabular}{|c|c|c|c|c|c|c|c|}
\hline Injury site $(n=25)$ & Front row & Second row & Back row & Half backs & Centres & Outside backs & Total \\
\hline Shoulders & 10 & 9 & 15 & 3 & 15 & 0 & 52 \\
\hline Ankle & 4 & 7 & 8 & 8 & 5 & 8 & 40 \\
\hline Hamstring & 0 & 0 & 2 & 3 & 6 & 13 & 24 \\
\hline Groin & 1 & 2 & 5 & 8 & 1 & 5 & 22 \\
\hline $\begin{array}{l}\text { Head (including } \\
\text { concussion) }\end{array}$ & 6 & 4 & 6 & 0 & 3 & 1 & 20 \\
\hline Calves & 0 & 1 & 1 & 4 & 2 & 8 & 16 \\
\hline Lower back & 7 & 5 & 1 & 0 & 0 & 0 & 13 \\
\hline Quadriceps & 0 & 1 & 2 & 0 & 2 & 1 & 6 \\
\hline Knee & 2 & 0 & 2 & 1 & 0 & 1 & 6 \\
\hline Wrist and hand & 1 & 0 & 3 & 0 & 1 & 0 & 5 \\
\hline Other* & 2 & 1 & 0 & 0 & 0 & 0 & 3 \\
\hline Neck and spine & 0 & 1 & 0 & 0 & 0 & 0 & 1 \\
\hline Total & 33 & 31 & 45 & 27 & 35 & 37 & - \\
\hline
\end{tabular}

* Face, biceps, and tibialis anterior

Table 4. Conceptualization of injury prevention exercises

\begin{tabular}{|c|c|c|c|c|}
\hline \multirow[b]{2}{*}{ Higher order themes } & \multicolumn{3}{|c|}{ Number (\%) of responses } & \multirow[b]{2}{*}{ Select raw data representing responses to question } \\
\hline & $\begin{array}{l}\text { Private } \\
(n=10)\end{array}$ & $\begin{array}{l}\text { Public } \\
(n=14)\end{array}$ & $\begin{array}{l}\text { No-fee } \\
(n=1)\end{array}$ & \\
\hline $\begin{array}{l}\text { Strengthening target } \\
\text { areas }\end{array}$ & $6(60)$ & $6(43)$ & $1(100)$ & $\begin{array}{l}\text { 'Specific strength exercises in the gym that target the most } \\
\text { injury prone areas' } \\
\text { 'Shoulder girdle exercises to strengthen the soft tissues } \\
\text { in the shoulder impact area' } \\
\text { 'Neck strengthening' }\end{array}$ \\
\hline Eccentric work & $4(40)$ & $2(14)$ & $1(100)$ & $\begin{array}{l}\text { 'Nordic hamstring lows' } \\
\text { 'Eccentric work' }\end{array}$ \\
\hline $\begin{array}{l}\text { Balance, stability, } \\
\text { and movement } \\
\text { exercises }\end{array}$ & $3(30)$ & $4(29)$ & $0(0)$ & $\begin{array}{l}\text { 'Stability and movement work' } \\
\text { 'Mobility exercises of all joints' } \\
\text { 'Balance and stability' }\end{array}$ \\
\hline Core & $1(10)$ & $3(21)$ & $1(100)$ & $\begin{array}{l}\text { 'Core stability and strength in all positions to ensure correct } \\
\text { posture and spine alignment' } \\
\text { 'Planking is used for front rowers for core stability' }\end{array}$ \\
\hline Flexibility & $2(20)$ & $1(7)$ & $0(0)$ & $\begin{array}{l}\text { 'Stretching and yoga' } \\
\text { 'Flexibility' } \\
\text { 'PNF stretches' }\end{array}$ \\
\hline Recovery techniques & $1(10)$ & $0(0)$ & $0(0)$ & 'Correct stretching and recovery techniques' \\
\hline Plyometrics & $1(10)$ & $0(0)$ & $0(0)$ & $\begin{array}{l}\text { 'High speed exertions (box jumps) to mimic the explosiveness } \\
\text { of sprinting' }\end{array}$ \\
\hline
\end{tabular}

PNF - proprioceptive neuromuscular facilitation 
Further, the quality of the recording was not assessed, which can be considered a limitation of the study. Thus, monitoring of injuries at an adolescent level in South African schoolboy rugby is an area that needs further attention, specifically for the development of injury prevention programs. Moreover, only 1 no-fee-paying school coach prescribed injury prevention exercises, although this should be an integral part of a rugby training program to ensure adequate preparation for high impact forces before play [22]. Recent position statements have identified the importance of strength and conditioning in identifying deficits in young players and addressing individual limitations [23]. While the majority of coaches implement some form of injury prevention, the techniques reported are limited and thus probably need to be adjusted to specific individuals or teams. The musculoskeletal system becomes more prepared for the demands of rugby and competition when the young player participates in a regular multifaceted strength and conditioning program [24]. Thus, developing an injury prevention protocol can assist players in benefitting from one of the most crucial aspects of a strength and conditioning program, reducing the risk of injury.

In the presented sample, the most commonly injured position was the back row (29\%), which is probably owing to the predominance of tackling by players in these positions [3]. However, the majority of previous studies have found a negligible difference in injury risk between positional groups despite the varying demands $[4,25]$. This is further supported by a metaanalysis concerning elite rugby union injuries [1].

Shoulder injuries were the most frequently cited in this study (52 responses), which is in line with previous rugby-related studies in elite level players [4, 26]. The highest number of shoulder injuries were to the back row players and centres ( $n=15$ each), which seems reasonable since shoulder injuries are most common in the tackle situation, a crucial aspect of both these positions in both elite and adolescent players [4]. Despite this high incidence, only 2 coaches mentioned implementing shoulder injury prevention exercises for their back row and only 3 implemented these for their centres. Developing the soft tissue of the shoulder is critical for resisting external forces and increasing the stability of the joint; therefore, prehabilitation and specific strengthening exercises could reduce the risk of such injuries [27]. Shoulder injuries were also the most common type of injury in the front and second row ( $n=10$ and 9, respectively), which could also have been expected as front row forwards experience high impact forces on the shoulder during the scrum [28]. Similarly to the back row, the second row is involved in many contact situations, including tackling and rucking, where shoulder injuries could occur [7]. As with the back row players, little focus was placed on prehabilitation of the shoulders in second rowers.

Lower limbs, the most commonly injured anatomical site throughout all levels of rugby $(42-55 \%$ of all injuries) [4], were most frequently injured in backline players. Since the backline dominates the open running portion of the game at high speeds, lower limb injuries could originate from such movement patterns [4]. To combat this, eccentric hamstring exercises (Nordic hamstring lowers) were prescribed by 6 coaches in backline positions; they have proven to be effective in reducing the risk of injury in rugby [29, 30]. Nordic hamstring lowers reduce the risk of injury by increasing eccentric torque and shifting the torque-joint curve angle of the hamstrings to greater muscle lengths [9]. Eccentric work was also the second most prescribed method of injury prevention by the current cohort of coaches.

Overall, the back row received the highest number of injuries (with 45 responses) and the least injured position was half backs (with 27 responses). Current literature presents conflicting results on the most commonly injured position. These statistics could, however, be slightly skewed by the definition of injury used in each study. Injury surveillance guidelines were introduced in 2007 to address the lack of uniformity in classification systems (medical attention, time loss, and non-fatal catastrophic injuries) but current trends suggest most studies only use time loss injuries as a classification [3].

\section{Conclusions}

In conclusion, managing and preventing injuries is a primary goal of a strength and conditioning specialist job. The higher ranked rugby schools implement far more advanced injury prevention programs compared with no-fee-paying schools; however, their effectiveness cannot be compared owing to lack of injury data in no-fee-paying schools. It must be nevertheless considered that the no-fee-paying schools are subjected to a lower level of rugby playing competition compared with schools in the top 100 rugby rankings. The no-fee-paying schools face opponents with similar attributes to theirs and within similar geographical areas. It could very well be the case that these schools experience fewer player injuries. Despite these potential phenomena, injury prevention should be one of the 
most important training goals of a school's pre-season regimen. To improve the pool of talented rugby players in South Africa, athletic development should begin with reducing the frequency and severity of injuries experienced on the rugby field. An appropriately designed and administered strength and conditioning program can benefit not only performance but also the risk of injuries in adolescent athletes and should form part of the South African long-term player development plan. A first call for action should be coach education to ensure that these individuals know how to record and prevent injuries and see the value of this.

\section{Practical applications}

The findings of the current investigation can be used as a tool to educate coaches and players on the main injuries that occur during rugby union activity. The fact that most coaches base their programs on anecdotal evidence means that this is imperative for the design of scientifically based injury prevention and strength and conditioning programs to reduce overall injury risk. Furthermore, the results can be applied in future research for comparison and to diversify the injury prevention practices that are being implemented by coaches and specialists.

\section{Disclosure statement}

No author has any financial interest or received any financial benefit from this research.

\section{Conflict of interest}

The authors state no conflict of interest.

\section{References}

1. Williams S, Trewartha G, Kemp S, Stokes K. A metaanalysis of injuries in senior men's professional rugby union. Sports Med. 2013;43(10):1043-1055; doi: 10.1007/s40279-013-0078-1.

2. Constantinou D, Bentley A. Injuries at Johannesburg high school rugby festivals. S Afr J Sports Med. 2015; 27(2):46-49; doi: 10.7196/SAJSM.596.

3. Viviers PL, Viljoen JT, Derman W. A review of a decade of rugby union injury epidemiology: 2007-2017. Sports Health. 2018;10(3):223-227; doi: 10.1177/194173811 8757178 .

4. Brooks JHM, Fuller CW, Kemp SPT, Reddin DB. Epidemiology of injuries in English professional rugby union: part 1 match injuries. Br J Sports Med. 2005; 39(10):757-766; doi: 10.1136/bjsm.2005.018135.

5. Bathgate A, Best JP, Craig G, Jamieson M. A prospective study of injuries to elite Australian rugby union players. Br J Sports Med. 2002;36(4):265-269; doi: 10.1136/bjsm.36.4.265.
6. Fuller CW, Taylor A, Kemp SPT, Raftery M. Rugby World Cup 2015: world rugby injury surveillance study. Br J Sports Med. 2017;51(1):51-57; doi: 10.1136/bjsports-2016-096275.

7. Fuller CW, Brooks JHM, Cancea RJ, Hall J, Kemp SPT. Contact events in rugby union and their propensity to cause injury. Br J Sports Med. 2007;41(12):862-867; doi: 10.1136/bjsm.2007.037499.

8. Hendricks S, Lambert M. Tackling in rugby: coaching strategies for effective technique and injury prevention. Int J Sports Sci Coach. 2010;5(1):117-135; doi: 10.1260/ 1747-9541.5.1.117.

9. Nicol A, Pollock A, Kirkwood G, Parekh N, Robson J. Rugby union injuries in Scottish schools. J Public Health. 2011;33(2):256-261; doi: 10.1093/pubmed/ fdq047.

10. Palmer-Green DS, Stokes KA, Fuller CW, England M, Kemp SPT, Trewartha G. Match injuries in English youth academy and schools rugby union: an epidemiological study. Am J Sports Med. 2013;41(4):749-755; doi: 10.1177/0363546512473818.

11. Quarrie KL, Hopkins WG. Tackle injuries in professional rugby union. Am J Sports Med. 2008;36(9):17051716; doi: 10.1177/0363546508316768.

12. Freitag A, Kirkwood G, Scharer S, Ofori-Asenso R, Pollock AM. Systematic review of rugby injuries in children and adolescents under 21 years. Br J Sports Med. 2015;49(8):511-519; doi: 10.1136/bjsports-2014 -093684 .

13. Clark DR, Roux C, Noakes TD. A prospective study of the incidence and nature of injuries to adult rugby players. S Afr Med J. 1990;77(11):559-562.

14. Tee JC, Lebatie F, Till K, Jones B. Injury incidence and characteristics in South African school first team rugby: a case study. S Afr J Sports Med. 2017;29(1):1-7; doi: 10.17159/2078-516x/2017/v29i0a1532.

15. Junge A, Cheung K, Edwards T, Dvorak J. Injuries in youth amateur soccer and rugby players - comparison of incidence and characteristics. Br Sports Med. 2004; 38(2):168-172; doi: 10.1136/bjsm.2002.003020.

16. Department of Basic Education. Education statistics in South Africa 2014. Pretoria: Department of Basic Education; 2016. Available from: https://www.education.gov.za/Portals/0/Documents/Publications/Education $\% 20$ Statistics $\% 202014$.pdf?ver=2016-05-13144159-067.

17. Wilmot PD, Dube C. Opening a window onto school geography in selected public secondary schools in the Eastern Cape province. S Afr Geogr J. 2016;98(2):337350; doi: 10.1080/03736245.2015.1028989.

18. Jones TW, Smith A, Macnaughton LS, French DN. Strength and conditioning and concurrent training practices in elite rugby union. J Strength Cond Res. 2016; 30(12):3354-3366; doi: 10.1519/JSC.000000000000 1445.

19. Jones TW, Smith A, Macnaughton LS, French DN. Variances in strength and conditioning practices in elite 


\section{HUMAN MOVEMENT}

L. Pote, B. Robinson, C. Christie, Rugby injuries

rugby union between the northern and southern hemispheres. J Strength Cond Res. 2017;31(12):3358-3371; doi: 10.1519/JSC.0000000000001773.

20. Pote L, Christie CJ. Strength and conditioning practices of university and high school level cricket coaches: a South African context. J Strength Cond Res. 2016; 30(12):3464-3470; doi: 10.1519/JSC.000000000000 1432.

21. Braun V, Clarke V. Using thematic analysis in psychology. Qual Res Psychol. 2006;3(2):77-101; doi: 10.1191/ 1478088706qp063oa.

22. Meir R, Diesel W, Archer E. Developing a prehabilitation program in a collision sport: a model developed within English premiership rugby union football. Strength Cond J. 2007;29(3):50-62.

23. Lloyd RS, Faigenbaum AD, Stone MH, Oliver J, Jeffreys I, Moody JA, et al. Position statement on youth resistance training: the 2014 International Consensus. Br J Sports Med. 2014;48(7):498-505; doi: 10.1136/ bjsports-2013-092952.

24. Faigenbaum AD, Myer GD. Resistance training among young athletes: safety, efficacy and injury prevention effects. Br J Sports Med. 2010;44(1):56-63; doi: 10.1136/bjsm.2009.068098.

25. Quarrie KL, Alsop JC, Waller AE, Bird YN, Marshall SW, Chalmers DJ. The New Zealand rugby injury and performance project. VI. A prospective cohort study of risk factors for injury in rugby union football. Br J Sports Med. 2001;35(3):157-166; doi: 10.1136/ bjsm.35.3.157.

26. Headey J, Brooks JHM, Kemp SPT. The epidemiology of shoulder injuries in English professional rugby union. Am J Sports Med. 2007;35(9):1537-1543; doi: 10.1177/ 0363546507300691.

27. Longo UG, Huijsmans PE, Maffulli N, Denaro V, De Beer JF. Video analysis of the mechanisms of shoulder dislocation in four elite rugby players. J Orthop Sci. 2011;16(4):389-397; doi: 10.1007/s00776-011-0087-6.

28. Quarrie KL, Wilson BD. Force production in the rugby union scrum. J Sports Sci. 2000;18(4):237-246; doi: 10.1080/026404100364974.

29. Opar DA, Williams MD, Shield AJ. Hamstring strain injuries. Sports Med. 2012;42:209-226; doi: 10.2165/ 11594800-000000000-00000.

30. Bourne MN, Opar DA, Williams MD, Shield AJ. Eccentric knee flexor strength and risk of hamstring injuries in rugby union: a prospective study. Am J Sports Med. 2015;43(11):2663-2670; doi: 10.1177/03635465 15599633. 